\title{
0232. Evaluation of HFNC'S wash out effect; a comparison of open- and closed-mouth models
}

\author{
N Nakamura*, M Kurota, T Watanabe, Y Onodera, H Suzuki, M Nakane, K Kawamae \\ From ESICM LIVES 2014 \\ Barcelona, Spain. 27 September - 1 October 2014
}

\begin{abstract}
Introduction
Although clinical studies of the high-flow nasal cannula (HFNC) and its effect on positive end-expiratory pressure (PEEP) have been performed, the mechanism of the washout effect and its relation with HFNC flow have not been well evaluated. Therefore, we made a respiratory model that can exhale with controllable end-tidal $\mathrm{PCO}_{2}$ $\left(\mathrm{P}_{\mathrm{ET}} \mathrm{CO}_{2}\right)$ to evaluate the washout effect of HFNC.Objective. To evaluate the quantitative results of HFNC's washout effect comparing open- and closed-mouth models.
\end{abstract}

\section{Methods}

Optiflow $^{\text {TM }}$ (Fisher and Paykel Healthcare, Auckland, NZ) was used as the HFNC system. The artificial respiratory model consisted of a lung model (the Dual Adult Training and Test Lung, Michigan Instruments Inc., Grand Rapids, MI, USA) and a ventilator (Puritan Bennett $^{\mathrm{TM}} 840$, Covidien, Dublin, Ireland). The HFNC and the respiratory model were connected by the airway model (Endotracheal Intubation Training Model LM059, Koken Co., Ltd., Tokyo, Japan). Respiratory settings were as follows: respiratory rate, 16 breaths/min; inspiratory time, 1 second; and tidal volume $\left(\mathrm{V}_{\mathrm{T}}\right), 300,500$, or $800 \mathrm{~mL} . \mathrm{CO}_{2}$ was infused into a distal site of the lung model to maintain $\mathrm{P}_{\mathrm{ET}} \mathrm{CO}_{2}$, measured just below the glottis, at $40 \mathrm{mmHg}$ at each $\mathrm{V}_{\mathrm{T}}$ setting without HFNC. HFNC flow was changed from 10-60 L/min in each $V_{T}$ setting, and the change of $\mathrm{P}_{\mathrm{ET}} \mathrm{CO}_{2}$ was measured in the open- and closed-mouth models.

\section{Results}

With any $\mathrm{V}_{\mathrm{T}}$ setting in the open-mouth model, $\mathrm{P}_{\mathrm{ET}} \mathrm{CO}_{2}$ quickly decreased to $20-25 \mathrm{mmHg}$ as HFNC started at $10 \mathrm{~L} / \mathrm{min}$. Thereafter, $\mathrm{P}_{\mathrm{ET}} \mathrm{CO}_{2}$ did not change with an increasing HFNC flow (Figure: solid lines). With the

Yamagata Unversity Faculty of Medicine, Anesthesiology and Intensive Care Medicine, Yamagata, Japan

\section{SpringerOpen $^{\odot}$}

closed-mouth model, $\mathrm{P}_{\mathrm{ET}} \mathrm{CO} 2$ gradually decreased as the HFNC flow was increased. The $\mathrm{V}_{\mathrm{T}}$ settings of 300 and $500 \mathrm{~mL}$ had the same trends and reached the bottom level of $22 \mathrm{mmHg}$ with HFNC flow over $50 \mathrm{~L} / \mathrm{min}$. The $\mathrm{V}_{\mathrm{T}}$ setting of $800 \mathrm{~mL}$ had a smaller decrease in $\mathrm{P}_{\mathrm{ET}} \mathrm{CO}_{2}$ to $28 \mathrm{mmHg}$ (Figure 1: dotted lines).

\section{Discussion}

Generation of PEEP by HFNC needs high flow as $35 \mathrm{~L} / \mathrm{min}$ to generate PEEP of $3 \mathrm{~cm} \mathrm{H}_{2} \mathrm{O}^{1)}$. In this study, it was demonstrated that HFNC's washout of the dead space is effective with relatively low flow as low as $10 \mathrm{~L} / \mathrm{min}$ in open-mouth model. HFNC flow of $10 \mathrm{~L} / \mathrm{min}$ can deliver gas of $166 \mathrm{~mL} / \mathrm{min}$, and this amount of gas delivery was thought to be enough to wash out the dead space during the exhalation time. The effect was weaker in the closedmouth model, but by increasing the HFNC flow produced an adequate effect. In this closed-mouth model, more gas leaked from the nostril instead of the mouth, and therefore,

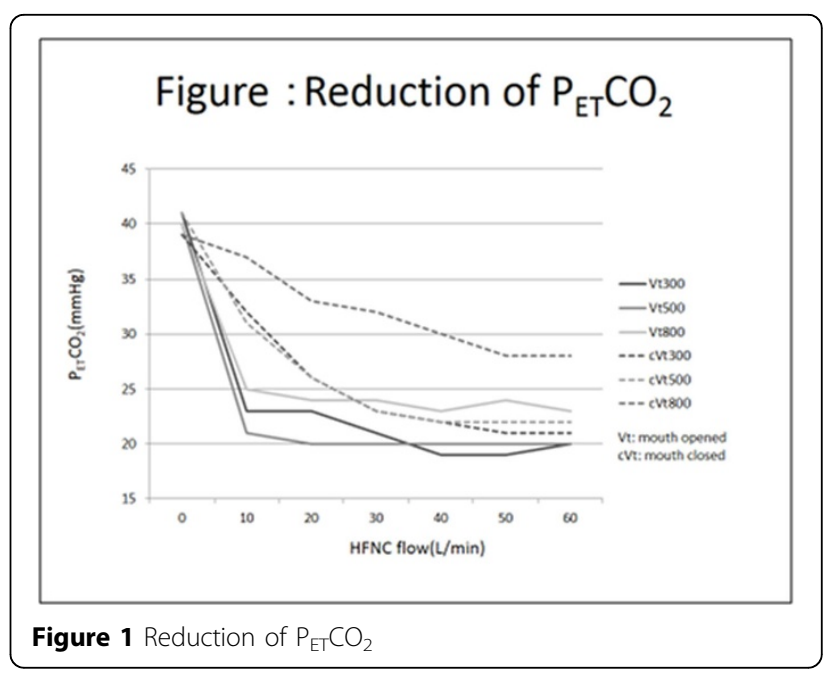
Attribution License (http://creativecommons.org/licenses/by/2.0), which permits unrestricted use, distribution, and reproduction in any medium, provided the original work is properly cited. 
less gas washed out the dead space, which caused a need for more HFNC flow to lower the $\mathrm{P}_{\mathrm{ET}} \mathrm{CO}_{2}$.

\section{Conclusions}

We concluded that the washout effect depends on HFNC flow especially with closed-mouth breathing while it may reach maximum with a relatively low flow of $10 \mathrm{~L} / \mathrm{min}$ with open-mouth breathing.

\section{Grant acknowledgment}

No conflict of interest.

Published: 26 September 2014

\section{Reference}

1. Parke R: Nasal high-flow therapy delivers low level positive airway pressure. Br J Anaesth 2009, 103:886-890.

doi:10.1186/2197-425X-2-S1-P16

Cite this article as: Nakamura et al:: 0232. Evaluation of HFNC'S wash out effect; a comparison of open- and closed-mouth models. Intensive Care Medicine Experimental 2014 2(Suppl 1):P16.

\section{Submit your manuscript to a SpringerOpen ${ }^{\mathcal{O}}$ journal and benefit from:}

- Convenient online submission

- Rigorous peer review

- Immediate publication on acceptance

- Open access: articles freely available online

- High visibility within the field

- Retaining the copyright to your article 